\title{
THE VORTEX FORMATION IN A HORIZONTAL FINITE CYLINDER BY ALTERNATING ELECTRIC CURRENT ${ }^{1}$
}

\author{
A. BUIKIS and H. KALIS
}

Institute of Mathematics Latvian Academy of Sciences and University of Latvia

Akadēmijas laukums 1, LV-1524 Rīga, Latvia

E-mail: lalumi@latnet. lv; kalis@lanet.lv

Received September 30, 2004; revised January 18, 2005

\begin{abstract}
We have investigated and calculated the distribution of electromagnetic fields and forces induced by a three- phase axially-symmetric system of electric current with six electrodes in a cylinder of a finite length $[1,3]$. In this paper the alternating current is fed to each of nine discrete circular conductors-electrodes, which are placed on the internal wall of the cylinder. This new mathematical model describes a real device [7], which transforms electric energy into heat.

The viscous incompressible flow of weakly electroconductive liquid-electrolyte is obtained by the finite-difference method, using the monotonous vector finite difference schemes. The average axially-symmetric motion of electrolyte and vortex distribution in a cylinder has been considered. The dependence of electromagnetic forces and velocity distribution at the inlet of the cylinder is investigated in the case of:

1) the vortex formation from the Lorentz force inside the cylinder by the electrode,

2) the vortex-breakdown from the swirl velocity at the inlet of the cylinder.
\end{abstract}

Key words: electroconductive liquid, vortex formation, electric current

\section{Introduction}

In many technological applications it is important to mix an electroconductive liquid using various magnetic fields [4]. In this work we consider a finite cylinder

$$
\tilde{\Omega}=\{(r, z): 0<r<a, 0<z<Z\}
$$

with nine metal coils-electrodes

$$
L_{i}=\left\{(r, z): \quad r=a, z=z_{i}\right\}, 0<z_{i}<Z, \quad i=1, \ldots, 9,
$$

\footnotetext{
${ }^{1}$ This work is partly financially supported by the project No 01.0130 of Latvian Science Council.
} 
positioned on it's inner surface with a fixed distance one from the other. Each of nine discrete circular conductors are fed with alternating current with density

$$
j_{i}=j_{0} \cos (\tilde{\omega} t+(i-1) \theta),
$$

here $j_{0}$ is the amplitude, $\tilde{\omega}=2 \pi f$ and $f$ are the angular frequency and frequency of the alternating current, $\theta=$ const is the phase and $t$ is the time. Usually we use $\theta=120^{\circ}, f=50 \mathrm{~Hz}$.

In the weakly conductive liquid-electrolyte the current creates the radial $B_{r}$ and axial $B_{z}$ components of the magnetic field as well as azimuthal component of the induced electric field $E_{\phi}$, which, in it's turn, creates axial $F_{z}$ and radial $F_{r}$ components of the electromagnetic force (due to the Lorentz force).

For calculation of the electromagnetic fields, the averaging method over the time interval $2 \pi / \tilde{\omega}=1 / f$ is used [1]. The averaged values of force $\left\langle F_{r}\right\rangle,\left\langle F_{z}\right\rangle$ give rise to a motion of liquid (electrolyte), which can be described by the stationary Navier-Stokes equation. At the inlet of the cylinder we have a uniform velocity $U_{0}$, but the swirl velocity is taken as the induced by the rigid body rotation with angular velocity $\Omega_{0}$.

The main aim of the work is to analyze the influence of different connection schemes of nine electrodes and swirl velocity at the inlet for vortex formation in the cylinder. In our previous works $[1,3]$ we have developed the mathematical model for calculation of the electromagnetic field with six electrodes and force by using elliptical integrals. This approach makes it possible the consideration of alternating current connections of various type, with phase shifts $\theta$ and various arrangements of the conductors.

\section{The Navier-Stokes equations}

The complete system of viscous incompressible flow consists of the continuity equation and the Navier-Stokes equations. The axially-symmetric stationary NavierStokes equations for vorticity function $\omega$, hydrodynamic-stream function $\psi$ and circulation $W$ are given in the cylindrical coordinates $(r, \phi, z)$ by the following system of non-dimensional equations [2,3]:

$$
\left\{\begin{array}{l}
\frac{R e}{r} J(\psi, \omega)=\frac{\partial^{2} \omega}{\partial z^{2}}+\frac{1}{r^{3}} \frac{\partial}{\partial r}\left(r^{3} \frac{\partial \omega}{\partial r}\right)+2 \operatorname{Re} \Gamma^{2} \frac{W}{r^{4}} \frac{\partial W}{\partial z}+\frac{\operatorname{ReTe}<f^{\phi}>}{r} \\
\frac{\operatorname{Re}}{r} J(\psi, W)=\Delta^{*}(W) \\
\Delta^{*}(\psi)=-r^{2} \omega
\end{array}\right.
$$

here

$$
J(\psi, b)=\frac{\partial \psi}{\partial r} \frac{\partial b}{\partial z}-\frac{\partial b}{\partial r} \frac{\partial \psi}{\partial z}
$$

is the Jacobian of the functions $\psi$ and $b$, where $b=\omega$ or $b=W$,

$$
<f^{\phi}>=\frac{\partial<F_{r}>}{\partial z}-\frac{\partial<F_{z}>}{\partial r}
$$


is the averaged azimuthal component of the force curl vectors,

$$
\Delta^{*}(g)=r \frac{\partial}{\partial r}\left(\frac{1}{r} \frac{\partial g}{\partial r}\right)+\frac{\partial^{2} g}{\partial z^{2}}
$$

is the conjugate expression for the Laplace operator of functions $g$ with $g=\psi$ or $g=W, \omega=\frac{1}{r} \omega_{\phi}, W=r v_{\phi}, \omega_{\phi}=\frac{\partial v_{r}}{\partial z}-\frac{\partial v_{z}}{\partial r}$ is the azimuthal component of the velocity curl vectors, $v_{r}=-\frac{1}{r} \frac{\partial \psi}{\partial z}, v_{z}=\frac{1}{r} \frac{\partial \psi}{\partial r}$ and $v_{\phi}$ are radial, axial and azimuthal components of the velocity, $\Gamma=\frac{V_{0}}{U_{0}}$ is the swirl number, $f^{\phi}$ is the dimensionless value of the curl of force, $R e=\frac{U_{0} r_{0}}{\nu}$ is the Reynolds number,

$$
T e=\frac{\sigma \tilde{\omega}}{\rho}\left(\frac{\mu j_{0}}{2 \pi U_{0}}\right)^{2}
$$

is the Taylor number, $\mu=4 \pi 10^{-7} \frac{\mathrm{m} \mathrm{kg}}{\mathrm{s}^{2} \mathrm{~A}^{2}}$ is the magnetic permeability in vacuum.

At the inlet of the cylinder we have the velocity $U_{0} \approx 0.1 \frac{\mathrm{m}}{\mathrm{s}}$ and the angular velocity $\Omega_{0} \approx 4 s^{-1}$.

The liquid has the following parameters: kinematic viscosity $\nu \approx 10^{-5} \frac{\mathrm{m}^{2}}{\mathrm{~s}}$, density $\rho \approx 1000 \frac{\mathrm{kg}}{\mathrm{m}^{3}}, \eta=\rho \nu$ is the dynamic viscosity, and the electric conductivity $\sigma \approx 100 \Omega^{-1} m^{-1}$.

The amplitude of the current density is $j_{0}=10^{6} \frac{\mathrm{A}}{\mathrm{m}^{2}}$. The radius $a$ of the cylinder is $0.05 \mathrm{~m}$, the length $Z$ of the cylinder is $0.35 \mathrm{~m}$.

We write equations (2.1) in the dimensionless form by scaling all the lengths to $r_{0}=a$ (the inlet radius of the tube), the axial velocity $v_{z}$ to $U_{0}$ (the uniform inlet axial velocity), swirl velocity to $W_{0}=r_{0} V_{0}$, the azimuthal velocity $v_{\phi}$ to $V_{0}=$ $r_{0} \Omega_{0}$, the vorticity $\omega$ to $\omega_{0}=U_{0} / r_{0}^{2}$ and stream function $\psi$ to $\psi_{0}=U_{0} r_{0}^{2}$.

We have the following dimensionless form of the boundary conditions:

$1)$ in the part of the inlet $\left(z=0,0 \leq r<r_{1}\right)$ the axial streams are assumed to have a uniform velocity $U_{0}$

$$
W=\omega=0, \quad \psi=0.5 r^{2},
$$

in the other part of the inlet $\left(z=0, r_{1} \leq r \leq 1\right)$ the swirl velocity profile is induced by the rigid body rotation with the angular velocity $\Omega_{0}$

$$
W=r^{2}, \quad \omega=0, \quad \psi=0.5\left(r_{1}^{2}+\beta\left(r^{2}-r_{1}^{2}\right)\right),
$$

2) the symmetry conditions along the axis $(r=0)$

$$
\psi=0, \quad W=0, \quad \frac{\partial \psi}{\partial r}=0, \quad \frac{\partial \omega}{\partial r}=0,
$$

3 ) the outflow boundary conditions at the outlet $(z=l=Z / a)$ 


$$
\frac{\partial \psi}{\partial z}=0, \quad \frac{\partial \omega}{\partial z}=\frac{\partial W}{\partial z}=0,
$$

4) the walls boundary conditions $(r=1)$

$$
W=0, \quad \psi_{w}=0.5\left(r_{1}^{2}+\beta\left(1-r_{1}^{2}\right)\right), \quad \omega=\omega_{w},
$$

where $\omega_{w}$ is the dimensionless wall-vorticity obtained within the frame of the finitedifference method from no-slip conditions [3], $r, r_{1}$ are the dimensionless coordinates, $\beta \approx 0.1$ is the velocity ratio of the coaxial free stream velocity to axial jet velocity $U_{0}$.

\section{The Finite-Difference Approximations}

The presence of large parameters at the first order derivatives $(\Gamma, R e)$ in the system of differential equations (2.1) causes additional numerical difficulties for the application of the general finite-difference schemes (a slow convergence rate, low precision). Thus special monotonous approximations are constructed in [2, 5], using functions of matrix and the exponential functions

$$
s(x)=\frac{x}{\exp (x)-1}>0, \quad s^{\prime}(x)=\frac{d s}{d x}<0, \quad s(0)=1, \quad s^{\prime}(0)=-0.5 .
$$

The Patankar approximations [6] are given in the following form:

$$
\begin{aligned}
& s(x)=\max \left((1-0.1|x|)^{5}, 0\right)+\max (-x, 0), \\
& s^{\prime}(x)=-0.5+0.5 \operatorname{signum}(x)\left(1-\max (1-0.1|x|, 0)^{4}\right) .
\end{aligned}
$$

Let us consider the 1D differential equation

$$
\frac{\partial}{\partial y}\left(\nu \frac{\partial u}{\partial y}\right)+b \frac{\partial u}{\partial y}=g(y), \quad b \geq 0, \nu>0
$$

the finite-difference equations associated with grid point $y_{k}$ are given in the form

$$
B_{k}\left(v_{k+1}-v_{k}\right)-A_{k}\left(v_{k}-v_{k-1}\right)=g_{k},
$$

where

$$
\begin{aligned}
& B_{k}=\frac{\nu_{k+0.5}}{h_{k+1} h_{k+0.5}} s\left(-\alpha_{k+0.5} h_{k+1}\right), \quad A_{k}=\frac{\nu_{k+0.5}}{h_{k} h_{k+0.5}} s\left(\alpha_{k-0.5} h_{k}\right), \\
& h_{k}=y_{k}-y_{k-1}, \quad \alpha=\frac{b}{\nu}, \quad u=\psi, \omega, W, \quad y=r, z, \\
& g_{k}=g\left(x_{k}\right), \quad p_{k \pm 0.5}=0.5\left(p_{k}+p_{k \pm 1}\right), \quad p=\nu, \alpha, h, \quad v_{k} \approx u\left(y_{k}\right) .
\end{aligned}
$$

For the system of two differential equations (3.2) $u$ is the vector $(\omega, W), y=z$ and we get the vector finite-difference equations with matrix-functions $A_{k}, B_{k}, s$ [5]. We consider a uniform grid:

$$
\begin{array}{r}
\omega_{h}=\left\{\left(r_{i}, z_{j}\right): r_{i}=h_{1} / 2+(i-1) h_{1}, \quad z_{j}=(j-1) h_{2}, \quad i=1, \ldots, n_{r},\right. \\
\left.j=1, \ldots, n_{z}, \quad n_{r} h_{1}=1, \quad n_{z} h_{2}=l\right\} .
\end{array}
$$

Subscripts $(i, j)$ refer to $r, z$ indices, the mesh steps in the $i, j$ directions are $h_{1}$ and $h_{2}$, respectively. The solution of the finite-difference scheme is calculated by using the under relaxation method. 


\section{Numerical Results}

The calculations are done for nine circular conductors $L_{i}$, which are arranged in the axial direction at the points

$$
z j=\left[z_{1}, z_{2}, z_{3}, z_{4}, z_{5}, z_{6}, z_{7}, z_{8}, z_{9}\right], \quad z_{i}=0.2 i, \quad i=1, \ldots, 9,
$$

where $z_{i}$ are the dimensionless coordinates.

The results of numerical experiments for $\left\langle F_{r}\right\rangle,\left\langle F_{z}\right\rangle,\left\langle f^{\phi}\right\rangle$ and $\psi, \omega, W$, in the dimensionless form were obtained with the help of the computer program MAPLE in the case of

$$
\theta=\frac{2 \pi}{3}, \quad h_{1}=h_{2}=0.1, \quad r_{1}=0.5, \quad \Gamma \in[0,8], \quad \operatorname{Re}=500, \quad \mathrm{Te}=0.1, \quad l=3 .
$$

The numerical results show that the force fields induced by alternating current are concentrated on the cylinder's surface in the vicinity of the circular electrodes. The results depend on the arrangement of electrodes.

If the parameter $\Gamma$ is increased, a vortex appears inside the cylinder, which, starting from $\Gamma>4$, is developing into a vortex system.

The dependence of values of averaged forces $\left\langle F_{z}\right\rangle,\left\langle F_{r}>\right.$, and curl of forces $<f^{\phi}>$ on the arrangement of nine conductors $n j=[123456789]$ follows from results presented in Table 1 .

Table 1. The extreme values of averaged forces and curl of forces.

\begin{tabular}{rcccc}
\hline No. & $n j$ & $\left\langle F_{z}\right\rangle$ & $\left\langle F_{r}\right\rangle$ & $\left\langle f^{\phi}\right\rangle$ \\
\hline 1 & {$[123456789]$} & {$[-17.7 ; 1.10]$} & {$[-11.9 ; 11.9]$} & {$[-1.4 ; 122]$} \\
2 & {$[135792468]$} & {$[-1.10 ; 17.7]$} & {$[-11.9 ; 11.9]$} & {$[-122 ; 0.6]$} \\
3 & {$[147258369]$} & {$[-69.0 ; 3.50]$} & {$[-50.5 ; 50.5]$} & {$[-49 . ; 200]$} \\
4 & {$[761835924]$} & {$[-51.1 ; 46.6]$} & {$[-36.8 ; 40.6]$} & {$[-247 ; 132]$} \\
5 & {$[531642789]$} & {$[-28.3 ; 47.5]$} & {$[-21.8 ; 26.3]$} & {$[-193 ; 195]$} \\
6 & {$[478591623]$} & {$[-31.4 ; 15.4]$} & {$[-20.3 ; 20.3]$} & {$[-59 . ; 188]$} \\
7 & {$[963852741]$} & {$[-3.50 ; 69.0]$} & {$[-50.5 ; 50.5]$} & {$[-200 ; 49]$.} \\
8 & {$[258147369]$} & {$[-69.0 ; 3.50]$} & {$[-50.5 ; 50.5]$} & {$[-49 . ; 200]$} \\
9 & {$[369147258]$} & {$[-69.0 ; 3.50]$} & {$[-50.5 ; 50.5]$} & {$[-49 . ; 200]$} \\
10 & {$[159263748]$} & {$[-4.30 ; 8.50]$} & {$[-27.3 ; 27.3]$} & {$[-215 ; 88]$.} \\
11 & {$[192837465]$} & {$[-15.0 ; 18.4]$} & {$[-12.4 ; 20.8]$} & {$[-127 ; 126]$} \\
12 & {$[847362951]$} & {$[-8.50 ; 4.30]$} & {$[-27.3 ; 27.3]$} & {$[-88 . ; 215]$} \\
13 & {$[217635894]$} & {$[-37.1 ; 20.0]$} & {$[-39.5 ; 28.2]$} & {$[-59 . ; 170]$} \\
14 & {$[815246379]$} & {$[-20.1 ; 36.6]$} & {$[-29.2 ; 25.1]$} & {$[-122 ; 215]$} \\
15 & {$[159246837]$} & {$[-59.8 ; 24.0]$} & {$[-41.7 ; 35.5]$} & {$[-58 . ; 164]$} \\
16 & {$[135468792]$} & {$[-1.10 ; 17.7]$} & {$[-11.9 ; 11.9]$} & {$[-122 ; 0.6]$} \\
17 & {$[197286354]$} & {$[-23.7 ; 62.7]$} & {$[-40.6 ; 35.6]$} & {$[-233 ; 99]$.} \\
18 & {$[197365284]$} & {$[-18.2 ; 58.1]$} & {$[-49.3 ; 42.6]$} & {$[-210 ; 36]$.} \\
\hline
\end{tabular}


In Fig. 1-16 we can see the vortex and vortex-breakdown formation in the cylinder depending on the arrangement of electrodes and the parameter $\Gamma$. The labels on the coordinates axis are given by $10 r$ and $10 z$, where $r \in(0,1), z \in(0, l)$ are the dimensionless coordinates.

The dependence of dimensionless values $\psi_{\max }, W_{\max }, \omega \in\left[\omega_{\min }, \omega_{\max }\right]$ on different connections of electrodes and the parameter $\Gamma$ is investigated for $\mathrm{Te}=0.1$. The following results were obtained:

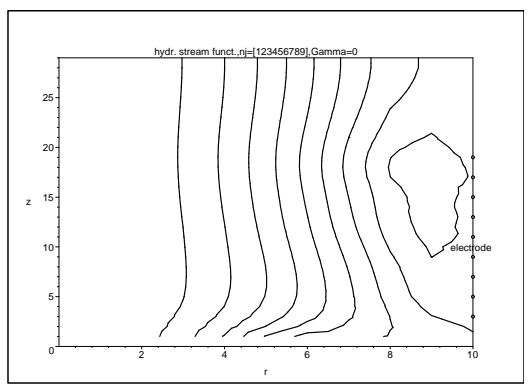

Figure 1. The stream functions for $n j=$ [123456789], $\psi \in(0.00,0.20), \Gamma=0$.

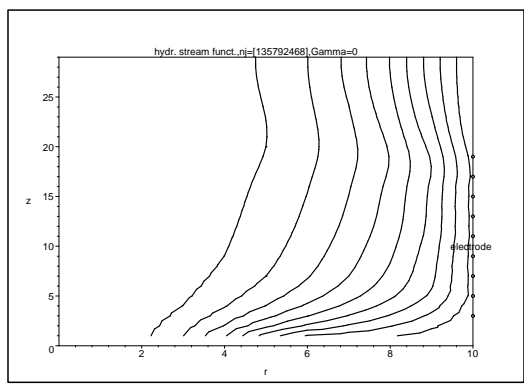

Figure 3. The stream functions for $n j=$ [135792468], $\psi \in(0.00,0.16), \Gamma=0$.

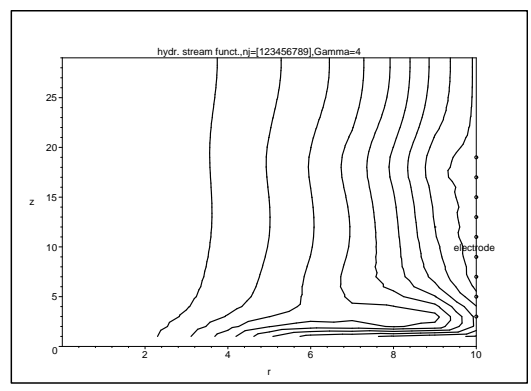

Figure 2. The stream functions for $n j=$ [123456789], $\psi \in(0.00,0.17), \Gamma=4$.

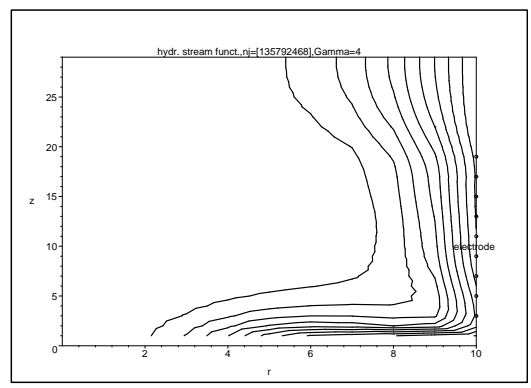

Figure 4. The stream functions for $n j=$ [135792468], $\psi \in(0.00,0.16), \Gamma=4$.

1. Conductors are connected in series, one after another, $n j=[123456789]$ (see the line No.1 in Table 1):

a) $\Gamma=0, \psi_{\max }=0.20, \omega \in[-1.1,6.9]$. Fig. 1 shows that a small vortex is developed at the electrode on the surface of the cylinder, which is induced by the Lorentz force; 
b) $\Gamma=4, \psi_{\max }=0.17, \omega \in[-15,6], W_{\max }=0.58$. Fig. 2 shows that vortex, induced by the electrode, vanishes and at the inlet of the cylinder streamlines deform, i. e., the vortex-breakdown from the swirling jets develops [3].

2. Conductors are connected to each other skipping one of them, thus $n j=$ [135792468] (see the line No.2 in Table 1):

a) $\Gamma=0, \psi_{\max }=0.16, \omega \in[-10,4]$. Fig. 3 shows that the flow is uniform in the cylinder without vortex;

b) $\Gamma=4, \psi_{\max }=0.16, \omega \in[-14,8], W_{\max }=0.54$. Fig. 4 shows that the streamlines are pressed at the wall of the cylinder.

3. Conductors are connected to each other skipping two of them, the ends of three wires are at the begin of electrodes, $n j=[147258369]$ (see the line No.3 in Table 1):

a) $\Gamma=0, \psi_{\max }=0.38, \omega \in[-9.0,70]$. Fig. 5 shows a large vortex at the last electrodes, induced by the Lorentz force;

b) $\Gamma=2, \psi_{\max }=0.36, \omega \in[-10,72], W_{\max }=0.68$. The vortex decreases at the electrodes, Fig. 16 shows the distribution of circulation $W$ in the cylinder;

c) $\Gamma=8, \psi_{\max }=0.29, \omega \in[-16,80], W_{\max }=0.72$. Fig. 6 shows that this vortex decreases and at the inlet of the cylinder and the vortex-breakdown develops from the swirling jets. The distribution of circulation $w$ is similar.

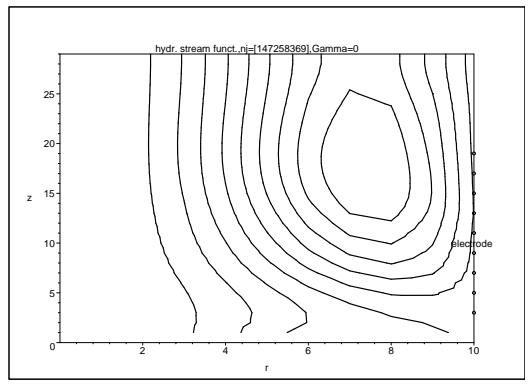

Figure 5. The stream functions for $n j=$ [147258369], $\psi \in(0.00,0.38), \Gamma=0$.

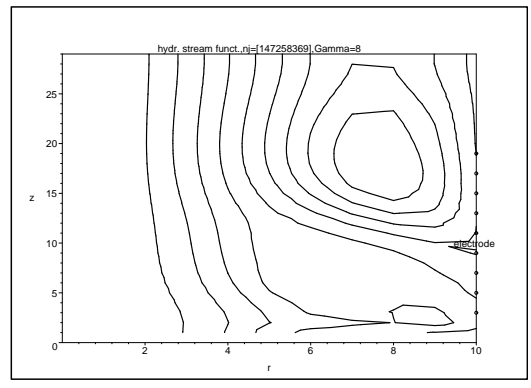

Figure 6. The stream functions for $n j=$ [147258369], $\psi \in(0.00,0.29), \Gamma=8$.

4.Two conductors are connected to wires in following form $n j=[761835924]$ (see the line No.4 in Table 1): $\Gamma=0, \psi_{\max }=0.17, \omega \in[-23,5]$. Fig. 7 shows a small vortex at the middle electrodes, induced by the Lorentz force.

5. The first six conductors are connected to each other skipping one of them, but the last three are connected in series, $n j=[531642789]$ (see the line No.5 in Table 1):

a) $\Gamma=0, \psi \in[-0.13,0.18], \omega \in[-35,7]$. Fig. 8 shows a big vortex at the first electrode, induced by the Lorentz force;

b) $\Gamma=4, \psi \in[-0.05,0.18], \omega \in[-47,12], W_{\max }=0.53$. Fig. 9 shows that the vortex decreases at the electrode and streamlines deform at the inlet; 


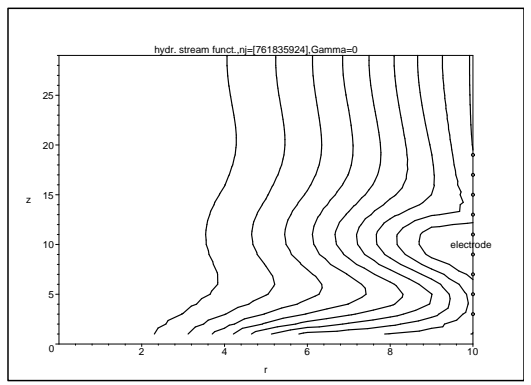

Figure 7. The stream functions for $n j=$ [761835924], $\psi \in(0.00,0.17), \Gamma=0$.

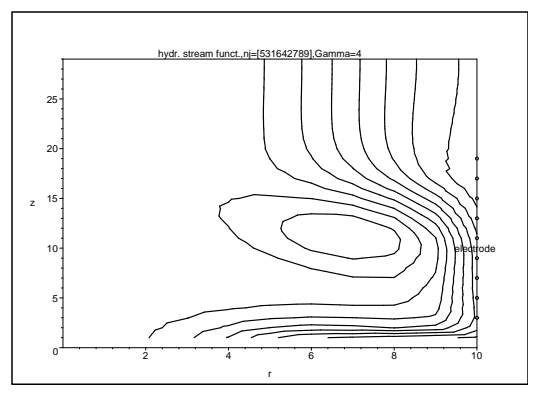

Figure 9. The stream functions for $n j=$ [531642789], $\psi \in(-0.05,0.18), \Gamma=4$.

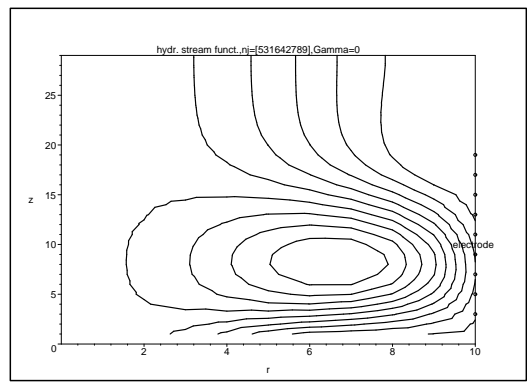

Figure 8. The stream functions for $n j=$ [531642789], $\psi \in(-0.13,0.18), \Gamma=0$.

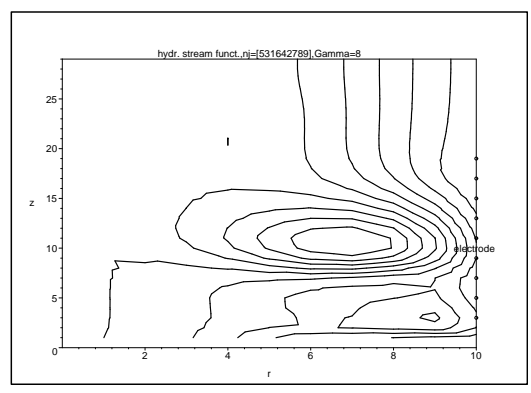

Figure 10. The stream functions for $n j=$ [531642789], $\psi \in(-0.17,0.17), \Gamma=8$.

c) $\Gamma=8, \psi \in[-0.17,0.17], \omega \in[-78,132], W_{\max }=0.56$. Fig. 10 shows that this vortex induced by the Lorentz force decreases and one vortice develops at the inlet;

d) $\Gamma=7, T e=0, \psi_{\max }=0.16, \omega \in[-19,7], W_{\max }=0.53$. Fig. 15 shows that at the inlet the vortex-breakdown develops from the swirling jets.

6. The ends of 3 wires are in the middle of electrodes, $n j=[478591623]$ (see the line No.6 in Table 1):

a) $\Gamma=0, \psi \in[0,0.26], \omega \in[-5,36]$. Fig. 11 shows a vortex at the last electrode, induced by the Lorentz force;

b) $\Gamma=4, \psi \in[0,0.22], \omega \in[-12,39], W_{\max }=0.62$. Fig. 12 shows two vortexes in the cylinder: the first vortex is due to the Lorentz force and the second one is due to vortex-breakdown from the swirling jets.

7. The ends of three wires are at the end of electrodes, $n j=[963852741]$ (see the line No.7 in Table 1):

a) $\Gamma=0, \psi \in[-0.32,0.16], \omega \in[-107,32]$. Fig. 13 shows a big vortex at the first electrode, induced by the Lorentz force; 


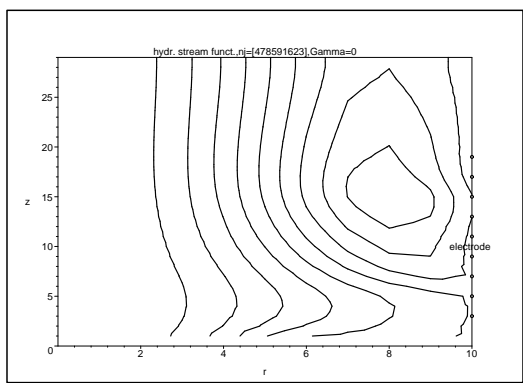

Figure 11. The stream functions for $n j=$ [478591623], $\psi \in(0.00,0.26), \Gamma=0$.

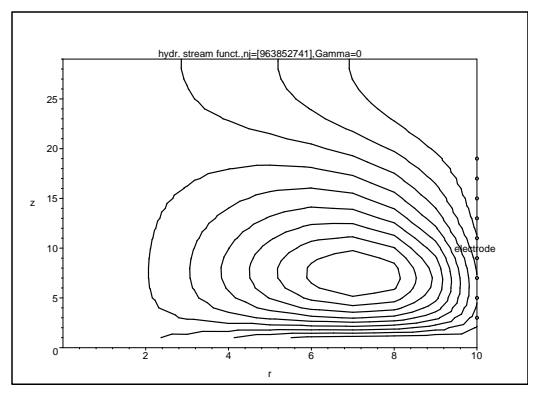

Figure 13. The stream functions for $n j=$ [963852741], $\psi \in(-0.32,0.16), \Gamma=0$.

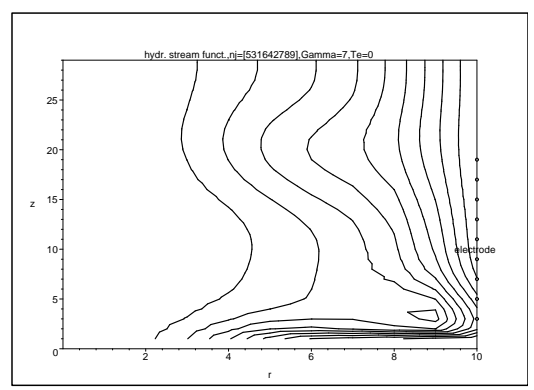

Figure 15. The stream functions for $\psi \in$ $(0,0.16), \Gamma=7, T e=0$.

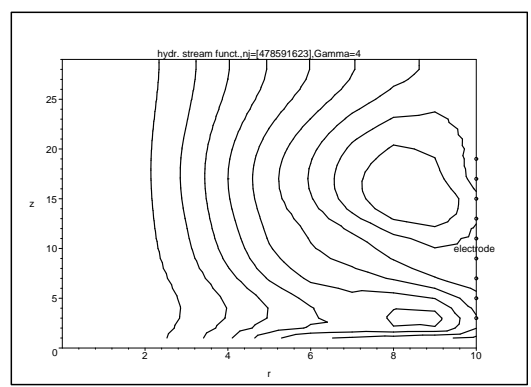

Figure 12. The stream functions for $n j=$ [478591623], $\psi \in(0.00,0.22), \Gamma=4$.

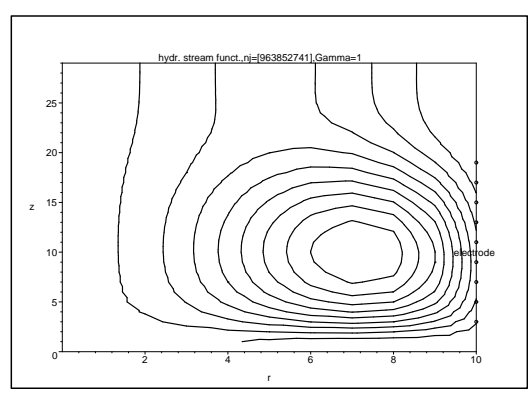

Figure 14. The stream functions for $n j=$ [963852741], $\psi \in(-0.43,0.17), \Gamma=1$.

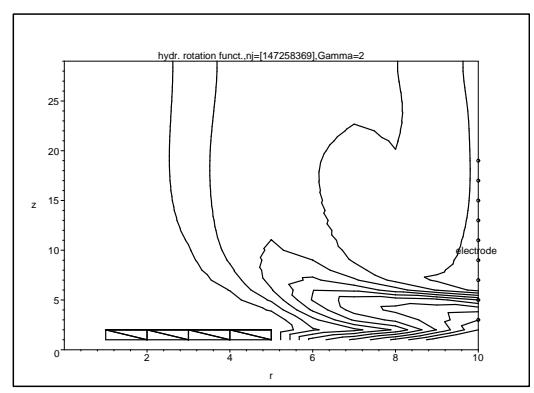

Figure 16. The rotation functions for $n j=$ [147258369], $W_{\max }=0.68, \Gamma=2$.

b) $\Gamma=1, \psi \in[-0.43,0.17], \omega \in[-108,41], \quad W_{\max }=0.53$. Fig. 14 shows that the vortex at the electrodes is deformed and moves up. 


\section{Conclusion}

Squirt motion of weakly electrically conducting fluid influenced by alternating electromagnetic field in a finite cylinder is investigated. A real variable approach is used to describe time-averaged electromagnetic forces and fields, induced by alternating current, which is fed to every of 9 discrete circular conductors. An original monotonous difference scheme for approximation of this mathematical model is developed. The reported results of the numerical experiments with 9 circular conductors can give some new physical conclusions about the flow behavior in the cylinder. The averaged values of the electric field, electromagnetic forces and the azimuthal component of the curl of forces vector are calculated for different arrangement of the electrodes. Using monotone finite-difference schemes for calculations the vortex formation from the Lorentz force inside the cylinder and the vortex-breakdown at the inlet of the cylinder are obtained. The distribution of the temperature is depending of the vortex formation in the cylinder $[1,3]$.

\section{References}

[1] A. Buikis and H. Kalis. Calculation of electromagnetic fields, forces and temperature in a finite cylinder. Mathematical Modelling and Analysis, 7(1), 21 - 32, 2002.

[2] A. Buikis and H. Kalis. Numerical modelling of heat and magnetohydrodinamics flows in a finite cylinder. Computational methods in applied mathematics, 2(3), 243 - 259, 2002.

[3] A. Buikis and H. Kalis. Flow and temperature calculation of electrolyte for a finite cylinder in the alternating field of finite number circular wires. Magnetohydrodynamics, 40(1), $77-90,2004$.

[4] J.Priede and Yu.Gelfgat. Mathematical model of the electromagnetic force induced by a rotating magnetic field a finite liquid column. Magnetohydrodynamics, 32(3), 272 - 280, 1996.

[5] H. Kalis. Special computational methods for solution of MHD problems. Magnetohydrodynamics, 30(2), 144 - 155, 1994. (in Russian)

[6] S. Patankar. Calculation of the heat transfer and fluid flow problems. Moscow, 1984. (in Russian)

[7] P. Verzbovics, A. Buikis and A. Bertasius. The device for the transformation electricity into heat energy. Patent P-02-189 of Republic Latvia, 20.07.2004, 2004.

\section{Sūkurio sudarymas horizontaliame baigtiniame cilindre kintama elektros srove}

\section{A. Buikis, H. Kalis}

Straipsnyje yra nagrinėjamas skysto elektrolito judejimas baigtiniame cilindre, veikiamas kintančio elektromagnetinio lauko. Panaudojant savo anksčiau sukurtą metodą suvidurkintų laike elektromagnetiniu jègų reikšmių gavimui, autoriai formuluoja stacionarų Navier-Stokso uždavini klampiam nespūdžiam elektrolito tekejjimui aprašyti. Sukurto matematinio modelio skaitiniam sprendimui yra pasiūloma originali monotoninẻ baigtinių skirtumų schema. Yra pateikiami skaitinių eksperimentų rezultatai su 9 žiediniais laidininkais-elektrolitais, tolygiai paskirstytais vidiniame cilindro paviršiuje. Autoriai analizuoja gaunamus cilindre srautus priklausomai nuo elektromagnetinių jègų pasiskirstymo (skirtingos elektrodų pajungimo schemos) ir sūkurinio greičio cilindro įejime. Labiausiai autorius domina sąlygos, kada cilindro viduje susidaro sūkuriai. 